Article

\title{
Scale-Model Experiments for the Surface Wave Influence on a Submerged Floating Ocean-Current Turbine
}

\author{
Katsutoshi Shirasawa *, Junichiro Minami and Tsumoru Shintake \\ Okinawa Institute of Science and Technology Graduate University, Onna, Okinawa 904-0495, Japan; \\ junichiro.minami@oist.jp (J.M.); shintake@oist.jp (T.S.) \\ * Correspondence: katsutoshi.shirasawa@oist.jp; Tel.: +81-98-966-8883 \\ Academic Editor: Aristides Kiprakis \\ Received: 24 February 2017; Accepted: 12 May 2017; Published: 16 May 2017
}

\begin{abstract}
In order to harness the kinetic energy of marine currents, we propose a novel ocean-current turbine with a horizontal axis. The turbine can be moored to the seabed and function similarly to kites in a water flow. To operate such turbines in a marine current, the resulting rotor torque needs to be canceled. Therefore, the proposed turbine is designed with a float at its top and a counterweight at its bottom. Thus far, we have verified the turbine stability and blade performance through towing experiments. As the next step, we constructed a scale-model turbine to confirm the mooring system. This experiment was performed at a circulating water channel with wave-making facilities. The influence of waves on the floating body was also investigated. In this paper, we report the behavior of the scale-model turbine moored to the tank bottom and discuss the influence of surface waves.
\end{abstract}

Keywords: ocean current; ocean-current turbine; ocean energy

\section{Introduction}

Ocean currents have excellent potential as a future renewable energy resource. Japan is suitably located for harnessing the power of ocean currents because the Kuroshio current runs steadily along its coastline. The Kuroshio current is an energy resource with low flow fluctuation regardless of the time of day or the season. The current flow is approximately $500 \mathrm{~m}$ deep and $100 \mathrm{~km}$ wide with a flow speed of 1-1.5 m/s [1,2]. Most research on extracting energy from a current flow has focused on ocean-current areas such as Japan, Florida (USA), and Taiwan, which face the Kuroshio current or Gulf Stream. Several groups have been developing ocean-current turbines where a floating body is moored to the seabed. Ocean-current turbines have many advantages for power production, including stability, availability of a large water flow, predictability of the flow speed, and no visual impact. On the other hand, research and development is technically difficult and potentially costly. To realize this power take-off system, many technical problems have to be solved regarding installation, cost maintenance, environment, and electricity transmission. Tidal-current turbine technologies have many features in common with ocean-current turbines. At the European Marine Energy Centre (EMEC), several tidal-current turbine projects are currently underway. Most of these projects have adopted horizontal-axis turbines mounted onto the seabed.

The key problem for ocean-current turbine systems is determining a method to cancel the resulting rotor torque. Therefore, we have proposed a novel turbine with a float on its top and counterweight on its bottom to cancel the undesirable rotor torque. Thus far, we have constructed a prototype turbine and conducted towing experiments to confirm the configuration of the float and counterweight. The prototype turbine has a three-blade rotor with a diameter of $2 \mathrm{~m}$ and an electric generator 
with an output of $1 \mathrm{~kW}$ [3]. Experimental results have verified the hydrostatic stability and stable power generation of the proposed turbine. As a next step, we conducted scale-model experiments in a circulating water channel to investigate the stability of the moored turbine in the middle layer. In addition, we confirmed the influence of surface waves on the body stability.

Another typical method for canceling undesirable rotor torque is to use a twin-turbine system. Such systems are equipped with counter-rotating rotors and generators. In the case of a twin-turbine system, each rotor must be controlled in order to maintain a balance between the torque and thrust. Our turbine is always stable owing to its float and counterweight configuration. The functions of electricity generation and body stabilization are clearly separated in our design. This provides more flexibility than turbine systems. For example, by adding a buoyancy control system to the float, the operation depth can simply be set to capture the optimum current.

Several groups have investigated the influence of surface waves on tidal turbine performance [4-7]. These researchers conducted experiments to measure the turbine performance with and without the presence of surface waves. They experimentally verified that surface waves have a significant impact on power production and blade loading. The most common tidal turbines are bottom-mounted. In contrast, our turbine is a submerged floating body. For practical design, it is important to consider the influence of waves on the mooring and floating body. Therefore, we focused on the motion of a turbine moored to the seabed.

The aim of the present work was to investigate a mooring system for our ocean-current turbine. In this paper, we first explain the principle of our turbine. Second, the construction of the scale-model turbine for mooring experiments is presented. Third, the mooring test performed in a circulating water channel to verify the stability of the mooring system is described. Finally, the conclusions are summarized.

\section{Theory}

\subsection{Ocean-Current Turbine}

Ocean currents run through deep areas of the sea. To convert the kinetic energy of an ocean current into electricity, a turbine must operate within the flow. A turbine must be moored to the seabed to operate at the middle layer of an ocean current. Figure 1 shows a schematic diagram of the proposed turbine system. The turbines are positioned approximately $100 \mathrm{~m}$ below the surface because the cross-section of the Kuroshio current is sufficiently large. A further advantage of working far from the sea surface is avoiding the influence of waves and wind, especially during a typhoon. According to the linear wave theory, the water particle velocity of a wave decays exponentially with depth in the deep-water case [8]. In practice, the operating depth should be decided based on the current profile and wave assessments.

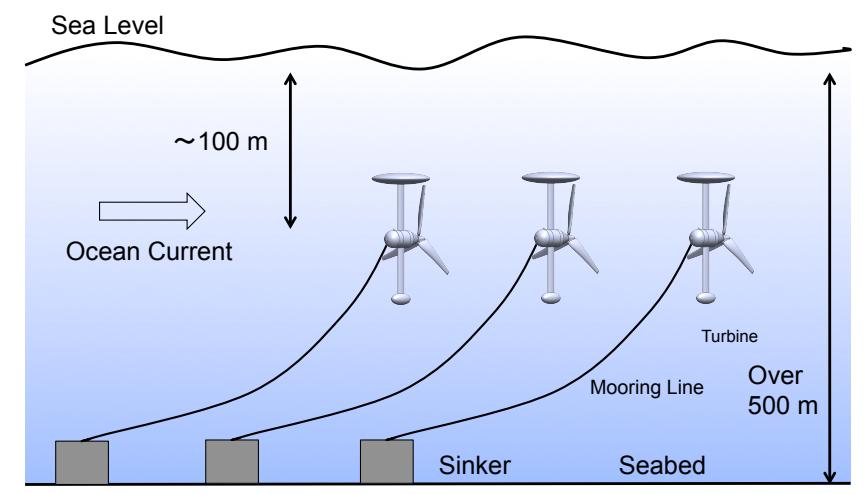

Figure 1. Schematic diagram of the ocean-current turbine. 
The proposed turbine uses a single horizontal-axis rotor to generate electricity, because horizontal-axis turbines generally have greater power efficiency than other turbines, such as vertical-axis turbines. As shown in Figure 2, the turbine is equipped with a float at its top and a counterweight at its bottom. Owing to buoyancy and gravitational forces, the turbine body maintains a stable attitude by canceling the rotor torque. In other words, buoyancy and gravity act together as a righting moment. Of course, this righting moment also provides stability during a pitching motion. Figure 3 shows the prototype turbine during the towing test at sea. The experimental results demonstrated that the developed ocean-current turbine has high hydrostatic stability and achieves stable power generation.

The power coefficient of the blade $C_{P}$ is given by:

$$
C_{P}=\frac{P}{\frac{1}{2} \rho A U^{3}}
$$

where $\rho$ is the seawater density, $A$ is the swept area, $U$ is the current speed, and $P$ is the power captured by a turbine blade. Assuming that the total efficiency is approximately $35 \%$ and the water flows at $1.5 \mathrm{~m} / \mathrm{s}$, the expected power output for an 80-m-diameter turbine is $3 \mathrm{MW}$. With today's marine technology, an 80-m rotor is very large. At the European Marine Energy Centre (EMEC) test site, the typical horizontal axis turbine has a rotor with a diameter of $18 \mathrm{~m}$ and a rated power of $1 \mathrm{MW}$ [9]. From an efficiency standpoint, an 80-m-diameter turbine is a reasonable plan for the future.

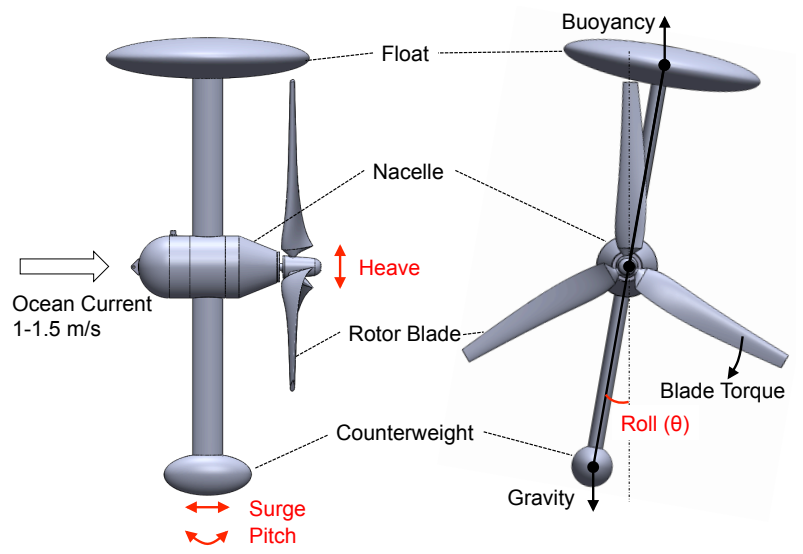

(a) Side view

(b) Back view

Figure 2. Schematic diagram of the ocean-current turbine. (a) Side view, (b) Back view.

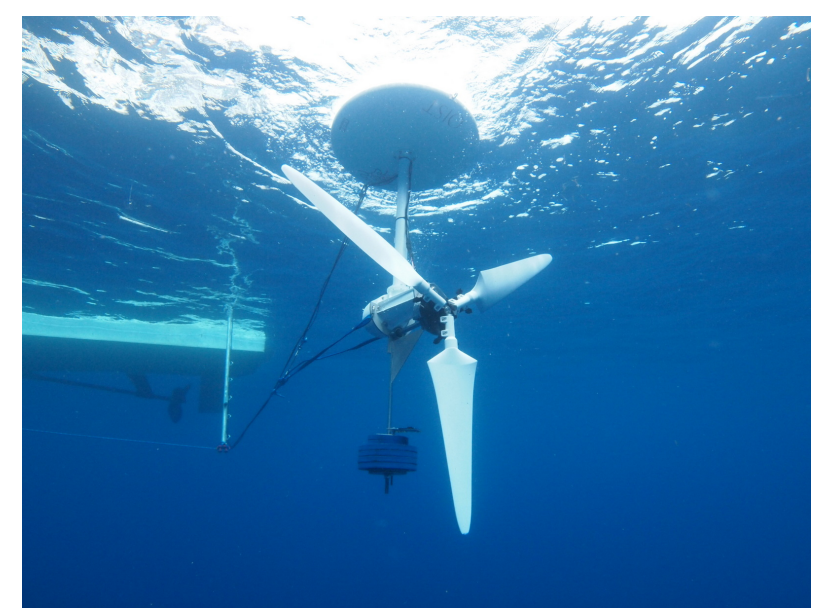

Figure 3. Photograph of the prototype turbine during the towing experiment at sea. The turbine has a 2-m-diameter three-blade rotor. 


\subsection{Mooring System}

In order to harvest the ocean current power, the ocean-current turbine should be in the flow. To avoid the influence of waves, our turbine works in the middle layer. The mooring method is important for stable operation and maintainability. For the turbine, the nacelle head is the best position for a connection point to the mooring line. In this case, the turbine naturally follows the current's direction. In other words, the moored turbine has a weathervane function. Therefore, it is not necessary to adjust the turbine direction. The nacelle structure supports the load of the turbine's thrust force. In addition, the float and counterweight are connected to this nacelle. Therefore, the nacelle is required to withstand the rotor torque.

As another method, the mooring line can be connected to the bottom of the counterweight. The merit of this mooring method is that it maintains the distance between the rotor and mooring line. To compensate for the pitch angle of the floating body, we may have to increase the lift force of the float. In addition, the support rod for the counterweight should be more massive. The large pitch angle decreases the turbine power efficiency.

The thrust coefficient of the blade $C_{T}$ is given by:

$$
C_{T}=\frac{T}{\frac{1}{2} \rho A U^{2}}
$$

where $T$ is the thrust force of the turbine. In water, the thrust force of a rotor is very large because of the high density of water. Therefore, a bottom-mounted tidal turbine has a massive foundation [9]. In our case, the mooring system must support the huge thrust force.

Synthetic ropes have been used in a wide range of demanding surface and subsea applications. Steel mooring components such as chains and stranded wire ropes are used exclusively. Synthetic fiber ropes can potentially be applied to develop cost-effective designs for the mooring systems of marine renewable energy devices [10]. The material of the mooring line for our ocean-current turbine should be synthetic rope. In this case, the elastic effect of the synthetic fiber can be important for mooring system dynamics. This property should be included in future design.

\section{Experimental}

The best way to demonstrate all systems is at sea. However, representing a real sea environment is difficult and not cost-effective as a first step. Thus, we conducted water tank tests.

\subsection{Experimental Setup}

In order to confirm the stability of the mooring system, we performed a circulating water channel test. Figure 4 shows a schematic diagram of the experimental setup. The experiment was carried out at a circulation water channel of the West Japan Fluid Engineering Laboratory Co., Ltd. (Nagasaki, Japan) [11]. The water channel is equipped with a wave generator. The test section is $48 \mathrm{~m}$ long, $4 \mathrm{~m}$ wide, and $1.67 \mathrm{~m}$ deep. The maximum flow speed is $2 \mathrm{~m} / \mathrm{s}$, and the maximum wave height is $0.3 \mathrm{~m}$. A plunger-type wave-maker is deployed at the upstream edge of the test section. This facility generates a two-dimensional surface wave in the downstream direction. The scale-model turbine position was set at the middle of the test section. A two-axis load cell was installed on the bottom to measure the mooring line tension. The mooring line was a stainless steel wire with a diameter of $0.3 \mathrm{~mm}$. Two-dimensional motion capture was used to observe the heave and surge motions of the scale-model turbine.

In this experiment, we adopted a simple mooring system to focus on the floating body motion under various wave conditions. The mooring line was connected to the head of the nacelle. A capacitance-type wave height meter was placed $1 \mathrm{~m}$ upstream from the load cell. The wave height and mooring line tension were recorded with an analog-to-digital (AD) converter connected to a personal computer. The sampling rate was $50 \mathrm{~Hz}$. 


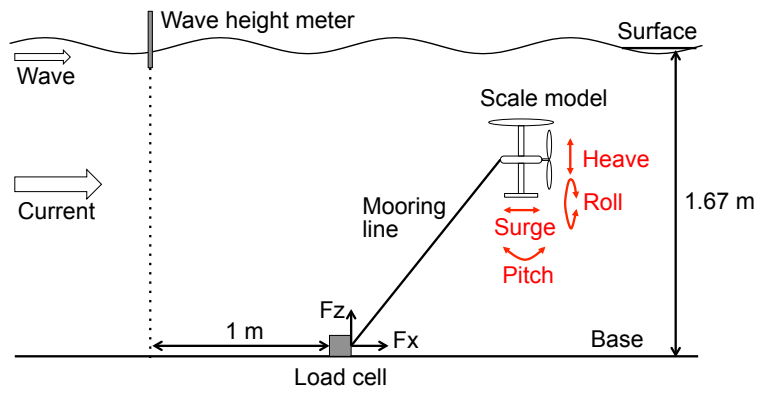

Figure 4. Schematic diagram of the experimental setup.

\subsection{Scale-Model Turbine}

We built a scale model of the ocean current turbine. Figure 5 shows a photograph and design drawing of the scale-model turbine. The diameter of the rotor was $250 \mathrm{~mm}$. The scale model had a torque limiter instead of an electric generator in the nacelle. The float was made of fiber-reinforced plastic (FRP) to generate buoyancy. The float had a shell structure. A spheroid-shaped float with a minor diameter of $50 \mathrm{~mm}$ and major diameter of $200 \mathrm{~mm}$ was attached to the top of the turbine. This float must generate buoyancy and have a low-drag shape. The float weighed $360 \mathrm{~g}$ in air, and the buoyancy was $7.5 \mathrm{~N}$. The counterweight was made of stainless steel and weighed $520 \mathrm{~g}$ in air. The buoyancy and weight were determined to satisfy the roll angle $\theta<5^{\circ}$ as defined in Figure 2 . In addition, the counterweight was adjusted to make the entire turbine system slightly positively buoyant. The buoyant force of the whole scale model was $0.2 \mathrm{~N}$. Four blades were used to keep the hub structure simple for easy assembly. We tuned the pitch angle of the rotor to match the experimental drag force. For commercial use, the number of blades should be determined according to the manufacturing cost, power efficiency, and maintainability. The shadow effect from the support structure will also be a concern because our turbine is a downwind type [12].
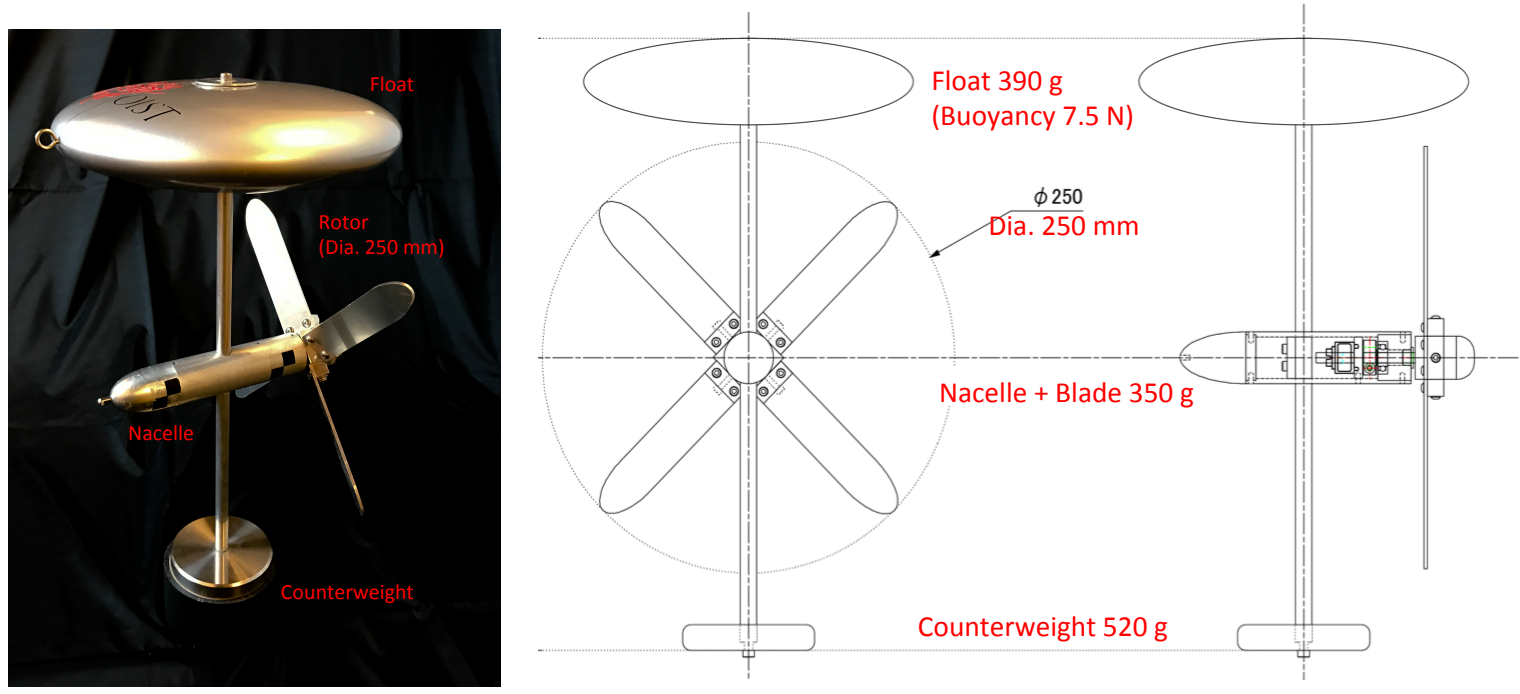

Figure 5. Photograph and design drawing of the scale-model turbine.

\subsection{Thrust Force Tuning}

The thrust force of the rotor was a key part of this experiment. In our blade design, the thrust coefficient $C_{T}$ was set to be from 0.6 to 0.7 . Before the mooring experiments, the thrust force was measured separately. The scale model had four blades to generate the thrust force. A torque limiter was placed in the nacelle to act as the load of the rotor. The torque limiter generated a constant torque 
with magnets. The thrust force was determined by tuning the pitch angle and load. In the following experiments, the blade pitch and load were chosen to satisfy $C_{T}=0.43$ for the $3 \mathrm{MW}$ case and $C_{T}=0.73$ for the $10 \mathrm{~kW}$ case. The $C_{T}$ values were not able to meet the design values accurately because of the scale-model mechanism.

\subsection{Scaling}

In many flows involving a liquid with a free surface, both the Reynolds number $(R e)$ and Froude number $(F r)$ are relevant non-dimensional parameters. Because it is not always possible to match both $R e$ and $F r$ between the model and prototype, we are sometimes forced to settle for an incomplete similarity. In other words, it was impossible to achieve complete similarity between the model and prototype in this case. For this kind of experiment, matching $F r$ was found to be more critical than matching $R e$. Fr is defined as:

$$
F r=\frac{U}{\sqrt{g L}}
$$

where $g$ is the gravitational acceleration, $U$ is the average liquid velocity at a cross-section, and $L$ is the characteristic length.

We assumed $3 \mathrm{MW}$ and $10 \mathrm{~kW}$ turbines for this experiment. We have been proposing a $10 \mathrm{~kW}$ ocean-current turbine for a feasibility study. The turbine is designed to generate $10 \mathrm{~kW}$ with a 5 -m-diameter rotor at a flow speed of $1.5 \mathrm{~m} / \mathrm{s}$. Table 1 lists $F r$ and $R e$ based on the turbine diameters under these conditions. In the $3 \mathrm{MW}$ turbine case, the current speed should be $1.5 \mathrm{~m} / \mathrm{s}$ to simulate the Kuroshio current. However, to meet Fr, the corresponding speed was $1.97 \mathrm{~m} / \mathrm{s}$ because the lowest flow speed of the water channel was $0.11 \mathrm{~m} / \mathrm{s}$.

Table 1. Experimental conditions for each turbine size.

\begin{tabular}{lcc|cc}
\hline Type & 10 kW Turbine & Scale Model & 3 MW Turbine & Scale Model \\
\hline Rotor diameter $(\mathrm{m})$ & 5 & 0.25 & 80 & 0.25 \\
Current speed $(\mathrm{m} / \mathrm{s})$ & 1.5 & 0.33 & 1.97 & 0.11 \\
Froude number & 0.21 & 0.21 & 0.07 & 0.07 \\
Reynolds number & $6.3 \times 10^{6}$ & $6.3 \times 10^{4}$ & $1.3 \times 10^{8}$ & $2.1 \times 10^{4}$ \\
Fluid & Seawater $\left(15^{\circ} \mathrm{C}\right)$ & Water $\left(10^{\circ} \mathrm{C}\right)$ & Seawater $\left(15^{\circ} \mathrm{C}\right)$ & Water $\left(10^{\circ} \mathrm{C}\right)$ \\
Kinematic viscosity & $1.188 \times 10^{-6}$ & $1.306 \times 10^{-6}$ & $1.188 \times 10^{-6}$ & $1.306 \times 10^{-6}$ \\
Scale ratio & - & $1 / 20$ & - & $1 / 320$ \\
Wave height (m) & 3.6 & 0.18 & 9.6 & 0.03 \\
Wave period (s) & 6.17 & 1.38 & 11.3 & 0.63 \\
Wavelength (m) & 59.4 & 2.97 & 198 & 0.62 \\
Wave steepness (Height/Wavelength) & \multicolumn{2}{c}{$0.061(1 / 16.5)$} & \multicolumn{2}{c}{$0.048(1 / 20.6)$} \\
Depth (m) & 33.4 & \multicolumn{3}{c}{2.69} \\
Relative depth (Depth/Wavelength) & \multicolumn{2}{c}{0.56} & \multicolumn{3}{c}{1.67} \\
\hline
\end{tabular}

\subsection{Surface Wave Influence}

Table 1 presents the waves selected for this study. The relative depth was set to greater than 0.5, which corresponds to the deep-water condition [8]. According to the linear wave theory, for a deep-water wave, the water particles within a wave travel with respective horizontal and vertical velocity components of:

$$
u=\frac{\pi H}{T} e^{k z} \cos (k x-\omega t)
$$

and:

$$
w=\frac{\pi H}{T} e^{k z} \sin (k x-\omega t)
$$


where $H$ is the wave height, $T$ is the wave period, $\omega=\sqrt{g k}$ is the dispersion relation connected to the wavelength, $g$ is the gravitational acceleration, $k=2 \pi / \lambda$ is the wavenumber, and $\lambda$ is the wavelength. Thus, for a given depth $z$, both $u$ and $w$ represent running waves with the same amplitude. The waves differ in phase by $\pi / 2$. In other words, the particle motions become circular for the deep-water case. The amplitude decreases from $\frac{\pi H}{T}$ at the surface to $e^{k z}$ times the surface amplitude at the depth $z$. This decrease is rather fast; at a depth equal to half the wavelength, the velocity amplitude is only about $4 \%$ of its surface value. In a deep-water case, the wavelength is given by:

$$
\lambda=\frac{g}{2 \pi} T^{2}=1.56 T^{2}
$$

A straightforward approach is superimposing linear wave theory onto a uniform current. Linear superposition can give a good approximation should the method of stretching the current profile be used. Figures 6 and 7 show the velocity profile of the water particle in the horizontal direction. The velocity profiles calculated from Equation (4) are based on the wave parameters given in Table 1 . The horizontal velocity variations mainly influence the rotor performance. Therefore, knowing the relative turbine position in the velocity profile is important to understanding the floating body motion. The initial turbine positions are also indicated in Figures 6 and 7. In Kuroshio current areas, the typical wave parameters are approximately $H=2 \mathrm{~m}$ and $T=7 \mathrm{~s}-10 \mathrm{~s}$ [13]. For the $3 \mathrm{MW}$ turbine, the wave parameters were determined to cover the typical wave. For the $10 \mathrm{~kW}$ turbine, the wavelength was set shorter than the typical wave because its deployment was planned for another inshore sea area [14]. Of course, there is a possibility of waves with larger amplitudes.

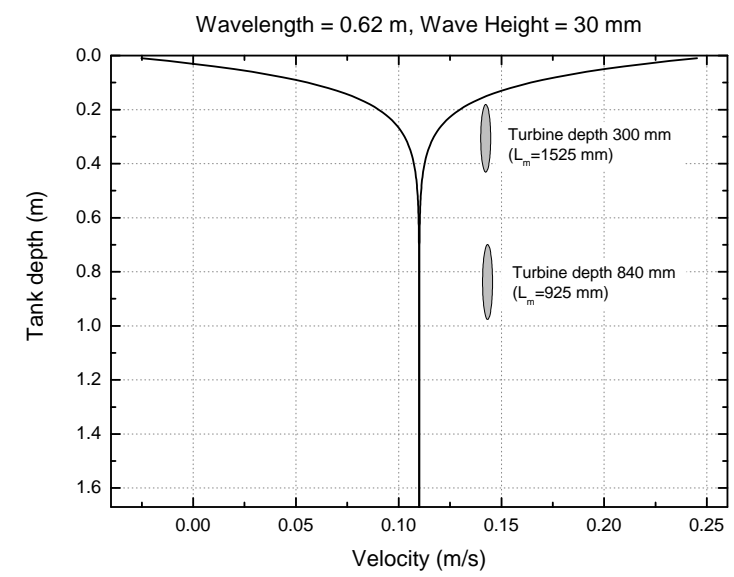

Figure 6. Horizontal velocity profile calculated with the linear wave theory: $3 \mathrm{MW}$ case.

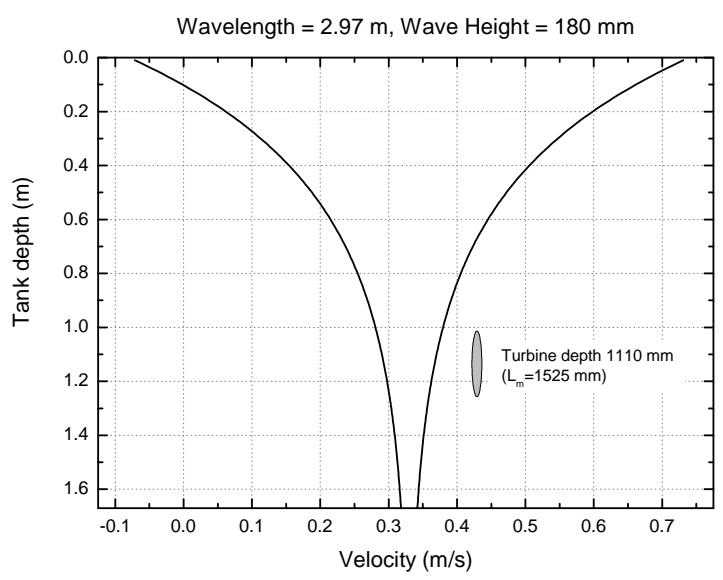

Figure 7. Horizontal velocity profile calculated with the linear wave theory: $10 \mathrm{~kW}$ case. 


\section{Results}

To avoid the influence of reflected waves, we analyzed data immediately after a steady state was achieved.

\subsection{MW Case}

The mooring line length was set at $1525 \mathrm{~mm}$. At $U=0 \mathrm{~m} / \mathrm{s}$, part of the float was slightly above the surface. The flow speed was then increased up to $0.11 \mathrm{~m} / \mathrm{s}$. The blades started to rotate, and the whole body went under the water because the turbine generated a thrust force from its rotation. The blade was set to generate a thrust force of $0.13 \mathrm{~N}\left(C_{T}=0.43\right)$. Then, the turbine reached an equilibrium state. The mooring line was stretched while the water was flowing. The nacelle depth was approximately $300 \mathrm{~mm}$, which corresponds to a depth of $96 \mathrm{~m}$ for the $3 \mathrm{MW}$ case. The system was very stable, and there was no transient phenomenon. Figure 8 shows a photograph of the scale model during the experiment (see also Movie S1 available online).

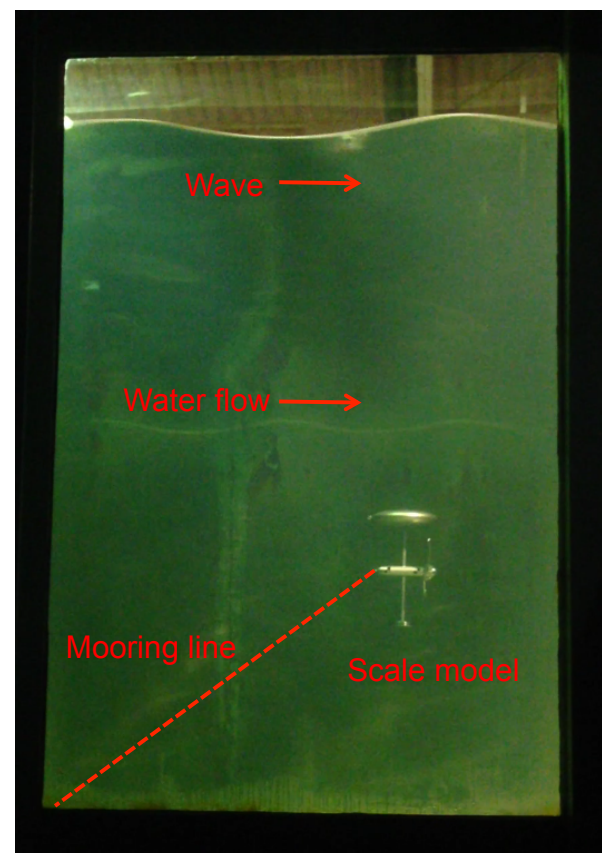

Figure 8. Photograph of the scale-model turbine during the tank experiment.

The turbine depth was roughly half the wavelength, as given in Table 1 . To investigate the influence of waves on the body motion, the wave amplitude was increased with the same wave period. The wavelengths were calculated with Equation (6). Table 2 presents the measured heave and surge motions for each wave parameter. All of the values were averaged for five periods just after periodic motion was observed. The measured surge and heave basically tended to grow in proportion to the wave condition. However, the values were small under several wave conditions. Figure 9 shows the wave height and mooring tension. Under these wave conditions, we could not generate ideal sinusoidal waves because of the backlash problem of the plunger driving mechanism.

The line relaxation caused a spike-like peak in the mooring tension. For the high wave height case shown in Figure 9c, we observed the mooring line being completely loose. At this moment, the line shape sagged down. The turbine was caught in a circular motion of the water particles. When the spike-like peaks appeared, the line shape was straight. Figure 9a,c show that the period of the spike peak was not the same as the wave period. These experimental results were considered to be due to the relation between the turbine depth and wave condition. In addition, the buoyant and drag forces of the whole floating body contributed to the turbine going back to its initial position. The restoring 
force and displacement by surface waves affected the spikes of the mooring line tension. Based on the above results, the working depth and mooring system should be carefully decided in practical applications. Of course, this kind of line relaxation should be avoided. The $F_{z}$ component variations of the line tension were slightly larger than those for $F_{x}$. This was probably caused by the shape of the float. The vertical particle motion seemed to act at the top of the float.

Table 2. Measured turbine motion and wave at a flow speed of $0.11 \mathrm{~m} / \mathrm{s}$. The operation period of the

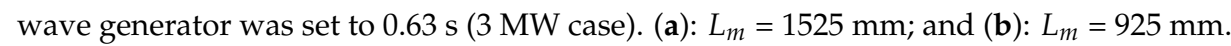

\begin{tabular}{|c|c|c|c|}
\hline \multicolumn{4}{|c|}{ (a) $L_{m}=1525 \mathrm{~mm}$} \\
\hline $\begin{array}{c}\text { Wave Height } \\
\text { (mm) }\end{array}$ & $\begin{array}{l}\text { Turbine Depth } \\
\text { (mm) }\end{array}$ & $\begin{array}{c}\text { Heave } \\
(\mathrm{mm})\end{array}$ & $\begin{array}{l}\text { Surge } \\
(\mathrm{mm})\end{array}$ \\
\hline 0 & 300 & 0 & 0 \\
\hline 10 & 340 & 0 & 4 \\
\hline 23 & 290 & 12 & 17 \\
\hline 25 & 300 & 7 & 10 \\
\hline 53 & 340 & 34 & 32 \\
\hline \multicolumn{4}{|c|}{ (b) $L_{m}=925 \mathrm{~mm}$} \\
\hline $\begin{array}{l}\text { Wave Height } \\
(\mathrm{mm})\end{array}$ & $\begin{array}{l}\text { Turbine Depth } \\
\text { (mm) }\end{array}$ & $\begin{array}{l}\text { Heave } \\
(\mathrm{mm})\end{array}$ & $\begin{array}{l}\text { Surge } \\
(\mathrm{mm})\end{array}$ \\
\hline 0 & 840 & 0 & 0 \\
\hline 9 & 800 & 5 & 2 \\
\hline 24 & 820 & 2 & 0 \\
\hline 25 & 790 & 2 & 0 \\
\hline 53 & 810 & 7 & 5 \\
\hline
\end{tabular}

To observe the influence of waves at different operating depths, we set the mooring line length at $925 \mathrm{~mm}$. The turbine depth was slightly greater than the wavelength. In this case, the waves did not influence the turbine. The measured tension had no variation, as shown in Figure 10. The surge and heave values were also small, as given in Table 2b (see also Movie S1 available online).
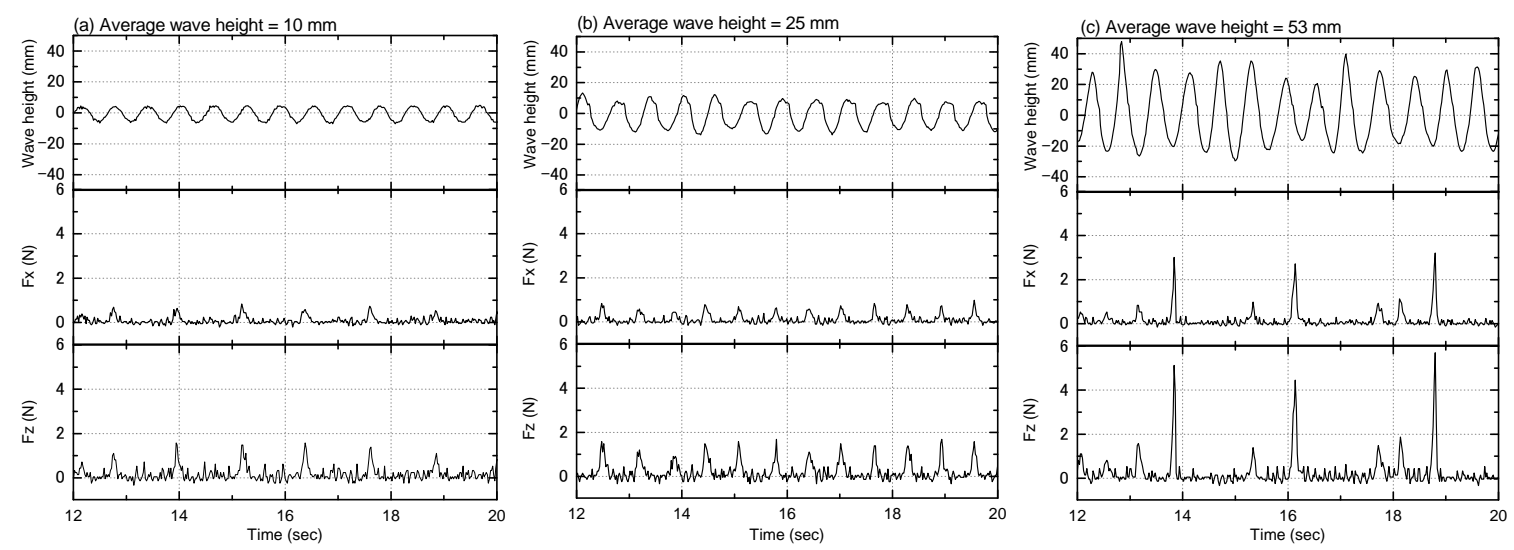

Figure 9. Wave height and mooring line tension: $L_{m}=1525 \mathrm{~mm}, U=0.11 \mathrm{~m} / \mathrm{s}, 3 \mathrm{MW}$ case. The operation period of the wave generator was set to $0.63 \mathrm{~s}$. (a) Average wave height $=10 \mathrm{~mm}$; (b) Average wave height $=25 \mathrm{~mm}$; (c) Average wave height $=53 \mathrm{~mm}$. 


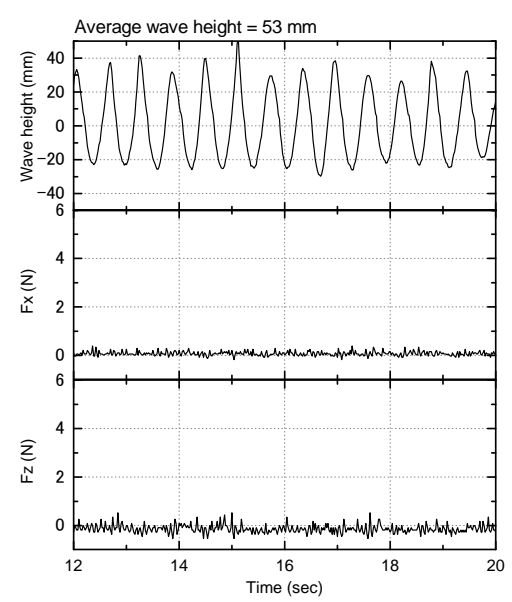

Figure 10. Wave height and mooring line tension: $L_{m}=925 \mathrm{~mm}, U=0.11 \mathrm{~m} / \mathrm{s}, 3 \mathrm{MW}$ case. The operation period of the wave generator was set to $0.63 \mathrm{~s}$.

\section{2. $10 \mathrm{~kW}$ Case}

The mooring line length was set at $1525 \mathrm{~mm}$. The flow speed was set to $0.33 \mathrm{~m} / \mathrm{s}$. Under the no-wave condition, the horizontal component $\left(F_{x}\right)$ of the line tension was $2.5 \mathrm{~N}$. In this case, $C_{T}=0.73$, and the thrust force of the rotor was $1.96 \mathrm{~N}$. The remaining force was caused by the other components. The vertical component $\left(F_{z}\right)$ was approximately $0.78 \mathrm{~N}$; this was mainly generated by the float, which had a slight positive angle of attack under this condition.

The turbine depth was shorter than the wavelength, as indicated in Table 1 . Thus, the wave influence could reach the turbine. The surge values were larger than the heave values, as indicated in Table 3. Figure 11 shows the measured mooring line tensions. The fluctuations in the graph resulted from surface waves. The mooring tension sinusoidally varied according to the wave height. The variation period matched the wave period. In this situation, the rotor blade received a cyclic load caused by the surface waves. In the case of Figure 11a, at the turbine depth, the horizontal flow speed variation was from $0.305 \mathrm{~m} / \mathrm{s}$ to $0.355 \mathrm{~m} / \mathrm{s}$ according to Equation (4). Consequently, the thrust force difference of the rotor was calculated to be $0.6 \mathrm{~N}$. This value is smaller than the measured Fx amplitude of $1.4 \mathrm{~N}$, because other parts were not considered. However, we can use this to predict the trend of the rotor thrust force.
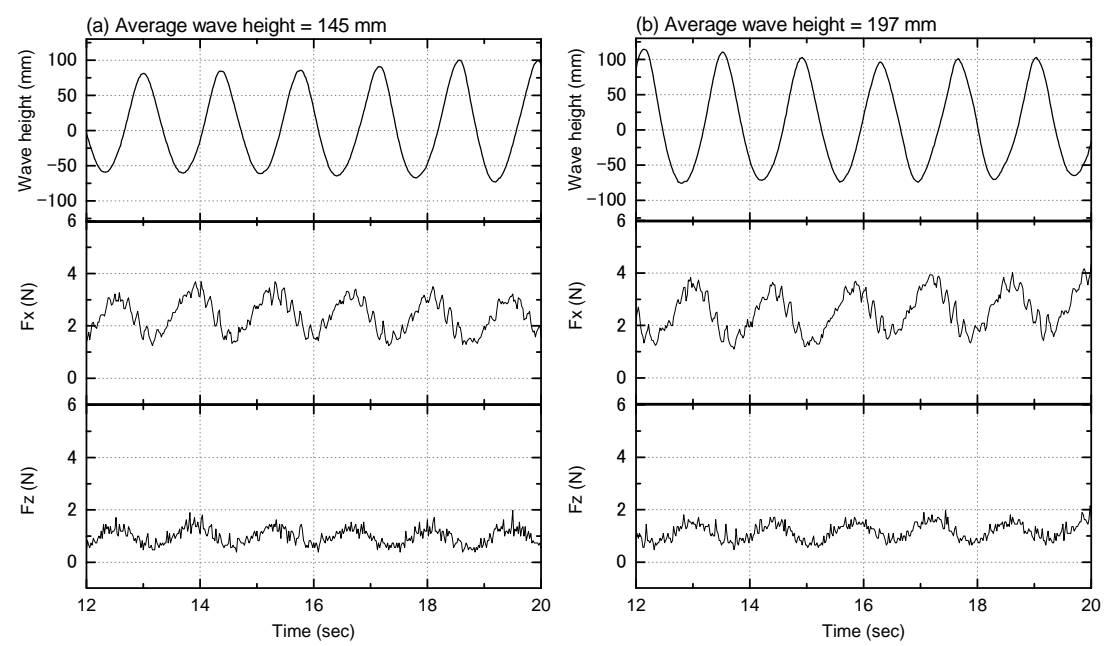

Figure 11. Wave height and mooring line tension: $L_{m}=1525 \mathrm{~mm}, U=0.33 \mathrm{~m} / \mathrm{s}, 10 \mathrm{~kW}$ case. The operation period of the wave generator was set to $1.38 \mathrm{~s}$. (a) Average wave height $=145 \mathrm{~mm}$; (b) Average wave height $=197 \mathrm{~mm}$. 
Table 3. Measured turbine motion and wave at a flow speed of $0.33 \mathrm{~m} / \mathrm{s}$. The operation period of the wave generator was set to $1.38 \mathrm{~s}$ (10 kW case).

\begin{tabular}{cccc}
\hline \multicolumn{4}{c}{$\mathbf{L}_{\boldsymbol{m}}=\mathbf{1 5 2 5} \mathbf{~ \mathbf { m m }}$} \\
\hline $\begin{array}{c}\text { Wave Height } \\
(\mathbf{m m})\end{array}$ & $\begin{array}{c}\text { Turbine Depth } \\
(\mathbf{m m})\end{array}$ & $\begin{array}{c}\text { Heave } \\
(\mathbf{m m})\end{array}$ & $\begin{array}{c}\text { Surge } \\
(\mathbf{m m})\end{array}$ \\
\hline 0 & 1110 & 0 & 0 \\
145 & 1200 & 16 & 39 \\
197 & 1300 & 9 & 31 \\
\hline
\end{tabular}

\section{Discussion}

Our proposed ocean-current turbine works at the middle layer of a water flow. This position allows for stable power generation while avoiding the influence of waves. In order to investigate the mooring stability of the ocean-current turbine, we conducted mooring tests with a scale model in a circulating water channel. The experiments demonstrated that our turbine design allows it to be stably moored to the seabed with a single mooring line. Furthermore, the influence of waves on the mooring system and floating body was investigated. When the wavelength is long relative to the turbine depth, the mooring method should be optimized to avoid the influence of surface waves in practical deployment. If the wave influence can reach the turbine position, the mooring system and turbine blade should be designed to withstand variations in the flow speed. Especially, cyclic loading accelerates the fatigue of the rotor blade. In addition, we should avoid resonance between the turbine, mooring, and waves. Alternatively, a turbine depth where the influence of waves does not reach should be chosen. The experimental results showed that linear wave theory is useful for predicting the influence of surface waves. In this work, several wave and turbine conditions were demonstrated. The turbine motion and mooring line tension were found to be reasonable from the viewpoint of linear wave theory.

The experimental conditions did not represent a practical sea environment. In the experiment, the directions of the waves and current flow were the same because of the arrangement of the equipment. The vertical shear of the ocean current should also be considered [15]. The influence of waves is an important consideration in the design of marine rotors and mooring lines-especially in terms of fatigue and sustainability.

In this experiment, we focused on the thrust force of the rotor. However, our turbine had a float and counterweight to maintain its attitude. Thus, the drag coefficient depended on the Reynolds number. When we design a turbine for use in marine currents, the influence of the Reynolds number should be considered. Computational fluid dynamics (CFD) analysis will be needed to optimize the entire turbine system. To do so, investigating the ocean currents will be important for defining realistic turbine operating conditions.

Supplementary Materials: The following are available online at www.mdpi.com/1996-1073/10/5/702/s1, Video S1: Movie of the scale-model turbine during the tank experiment.

Acknowledgments: Ohba of the Okinawa Institute of Science and Technology supported us in constructing the scale-model turbine. Hashizume and Kondo of the West Japan Fluid Engineering Laboratory Co., Ltd. supported us in carrying out the experiments. Iwashita and Tokunaga of Hiroshima University gave us useful advice on the experimental setup. This work was supported by the Okinawa Institute of Science and Technology Graduate University.

Author Contributions: Katsutoshi Shirasawa conducted the experiments, analyzed the data, and wrote the manuscript. Junichiro Minami supported the experimental works. Tsumoru Shintake contributed the fundamental design of the turbine system.

Conflicts of Interest: The authors declare no conflict of interest. 


\section{References}

1. Chang, Y.C.; Chu, P.C.; Tseng, R.S. Site selection of ocean current power generation from drifter measurements. Renew. Energy 2015, 80, 737-745.

2. Chen, F. Kuroshio power plant development plan. Renew. Sustain. Energy Rev. 2010, 14, 2655-2668.

3. Shirasawa, K.; Tokunaga, K.; Iwashita, H.; Shintake, T. Experimental verification of a floating ocean-current turbine with a single rotor for use in Kuroshio currents. Renew. Energy 2016, 91, 189-195.

4. Luznik, L.; Flack, K.A.; Lust, E.E.; Taylor, K. The effect of surface waves on the performance characteristics of a model tidal turbine. Renew. Energy 2013, 58, 108-114.

5. Barltrop, N.; Varyani, K.S.; Grant, A.; Clelland, D.; Pham, X.P. Investigation into wave-current interactions in marine current turbines. Proc. Inst. Mech. Eng. Part A 2007, 221, 233-242.

6. Galloway, P.; Myers, L.; Bahaj, A. Studies of a scale tidal turbine in close proximity to waves. In Proceedings of the Third International Conference and Exhibition on Ocean Energy, Bilbao, Spain, 6-8 October 2010.

7. Ai, K.; Avital, E.J.; Korakianitis, T.; Samad, A.; Venkatesan, N. Surface wave effect on marine current turbine, modelling and analysis. In Proceedings of the 7th International Conference on Mechanical and Aerospace Engineering (ICMAE), London, UK, 18-20 July 2016; pp. 180-184.

8. Dean, R.; Dalrymple, R. Water Wave Mechanics for Engineers and Scientists; Advanced Series on Ocean Engineering; World Scientific: Singapore, 1991.

9. The European Marine Energy Centre Ltd. Available online: http://www.emec.org.uk/ (accessed on 15 Febrary 2017).

10. Weller, S.D.; Johanning, L.; Davies, P.; Banfield, S.J. Synthetic mooring ropes for marine renewable energy applications. Renew. Energy 2015, 83, 1268-1278.

11. West Japan Fluid Engineering Co., Ltd. Available online: http://www.felco.ne.jp/felco/fel/ (accessed on 15 Febrary 2017).

12. Chen, F. The Kuroshio Power Plant; Lecture Notes in Energy; Springer International Publishing: Cham, Switzerland, 2013.

13. Webb, A.; Waseda, T.; Fujimoto, W.; Horiuchi, K.; Kiyomatsu, K.; Matsuda, K.; Miyazawa, Y.; Varlamov, S.; Yoshikawa, J. A High-Resolution, Wave and Current Resource Assessment of Japan: The Web GIS Dataset. In Proceedings of the 3rd Asian Wave and Tidal Energy Conference, Singapore, 24-28 October 2016; pp. 282-287.

14. Shirasawa, K.; Minami, J.; Shintake, T. Design of a 10-kW Ocean-current Turbine. In Proceedings of the 3rd Asian Wave and Tidal Energy Conference, Singapore, 24-28 October 2016; pp. 532-535.

15. Hanson, H.P. Subsurface Mooring Stability in the Presence of Vertical Shear. Mar. Technol. Soc. J. 2013, 47, 18-22.

(C) 2017 by the authors. Licensee MDPI, Basel, Switzerland. This article is an open access article distributed under the terms and conditions of the Creative Commons Attribution (CC BY) license (http:/ / creativecommons.org/licenses/by/4.0/). 